\title{
Formulae to Predict Elastic Axial Stresses Across the Transverse Edge of a Radial Circular Cross Bore in Thick Walled Cylinders
}

\author{
P. K. NZIU* and L. M. MASU \\ Department of Mechanical Engineering, Vaal University of Technology, South Africa.
}

ORCIDs: 0000-0002-5899-0700 (PK Nziu), 0000-0002-8544-6321 (Prof. LM Masu)

\begin{abstract}
Results of an analytical solution to predict axial stresses at the transverse edge of a radial circular cross bore in thick walled cylinders were presented and analysed in this work. A total of 35 analyses were conducted for different thickness ratios and cross bore sizes. The obtained analytical results were then validated on each analysis using Finite Element Analysis commercial software Abaqus. The developed solution was able to predict correctly axial stresses at the cross-bore intersection in 15 out of 35 models analysed.
\end{abstract}

Keywords: Pressure vessels, cross bore, transverse edge, axial stresses,

\section{INTRODUCTION}

In the design of pressure vessels, different types of principal stresses such as hoop, radial and axial stresses are used to calculate various forms of working stresses (Nziu and Masu, 2019a). he commonly used forms of working stresses are Tresca's and Von Mises theories (Comlecki et al, 2007). Numerous techniques such as analytical, experimental and numerical have been used to develop formulae to predict the aforesaid principal stresses (Masu, 1989). Though, the former is preferred due to its low cost (Nziu and Masu, 2019a).

A previous study by Nziu and Masu (2019b) had derived lengthy analytical solutions to predict stresses across the transverse edge of a radial circular cross bore. Because the stresses along the transverse edge of the cross bore are presumed to be critical (Ford and Alexander, 1977; Hearn, 1999). The developed analytical solutions are able predict stresses in both small and large cross bores. However, only the hoop stress results computed by the hoop stress solution along the transverse edge of a small radial circular cross bore were presented and analysed.

Therefore, this paper presents the analyses of the results predicted by axial stress solution as derived in Nziu and Masu (2019b) study.

\section{METHODOLOGY}

\section{Cross bore configuration}

The configuration of the radial circular cross along the transverse edge A-A is illustrated in Figure 1.

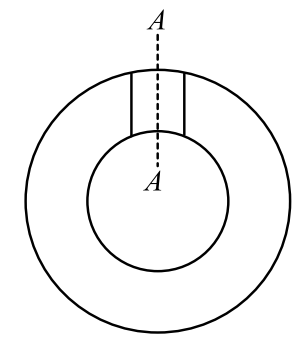

Figure 1: Configuration of the radial cross bore

Solution to predict axial stresses along transverse edge A-A of a radial circular cross bore

In the study by Nziu and Masu (2019b), the total stress distribution in the axial direction of the main cylinder was calculated by adding all the stresses acting in the axial direction. This summation was given by equations $3,7,8$ and 12 as indicated in Nziu and Masu (2019b) study. However, it was noted that the axial stress generated by the main cylinder at the cross-bore surface (computed using equation 3 ) was zero. Since this type of axial stress was being relieved by the cross bore. Hence, the total axial stress, $\sigma_{z_{\text {Total }}}$, along the transverse edge A-A of the cross bore was computed as shown in equations 1 and 2 .

$$
\begin{aligned}
& \sigma_{z_{\text {Total }}}=\sigma_{r_{2}}+\sigma_{r_{3 a}}+\sigma_{\theta_{3 b}} \\
& \sigma_{z_{\text {Total }}}=\frac{k^{2} m^{2} p_{i}}{k^{4} m^{4} \sin ^{2} \theta-1}\left(1-\frac{R_{0}^{2}}{R^{2}}\right) \\
&+\frac{1}{m^{2}-1}\left[m^{2} \sigma_{z}+p_{i}-m^{2} \frac{R_{i}^{2}}{r^{2}}\left(\sigma_{z}+p_{i}\right)\right] \\
&-\left(2 C+\frac{6 E}{r^{4}}+\frac{4 F}{r^{2}}\right) \cos 2 \theta
\end{aligned}
$$

Where

$\mathrm{r}$ Arbitrary radius measured from the cross bore bore centre

$p_{i} \quad$ Internal pressure.

$\sigma_{z} \quad$ local longitudinal stress at the surface of the cross bore

$\theta \quad$ Angle between the vertical axis and the small element. 
$\mathrm{K} \quad$ Cylinder thickness ratio

$R_{i} \quad$ Internal radius of the main bore.

$R_{O} \quad$ External radius of the main bore.

$r_{i} \quad$ Cross bore radius.

$\mathrm{R}$ Arbitrary radius measured from the main bore centre

m Ratio of $R_{O}$ and $r_{i}$,

\section{Studied Cases}

Seven cross bored thick-walled closed cylinders with thickness ratio of $1.4,1.5,1.75,2.0,2.25,2.5$ and 3.0 were studied. The analyses were done on five different cross bore sizes with bore ratios (cross bore to bore ratio) of $0.1,0.3,0.5,0.7$ and 1.0. A total of 35 analytical analyses was performed at this stage.

\section{Finite Element Analysis}

Finite Element Analyses (FEA) were performed using Abaqus software on 35 models of pressure vessels with similar geometric configuration to those given in the preceding section for purposes of validation.

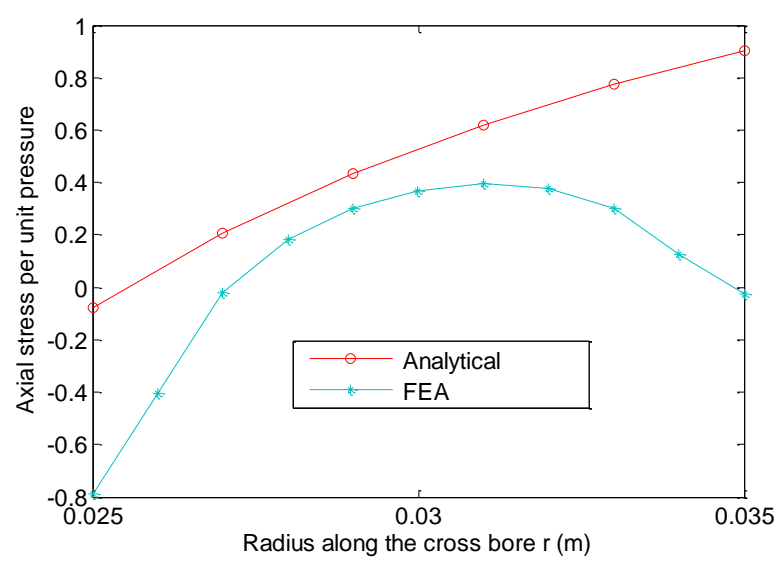

Figure 2: $\mathrm{K}=1.4 \mathrm{CB}=0.1$

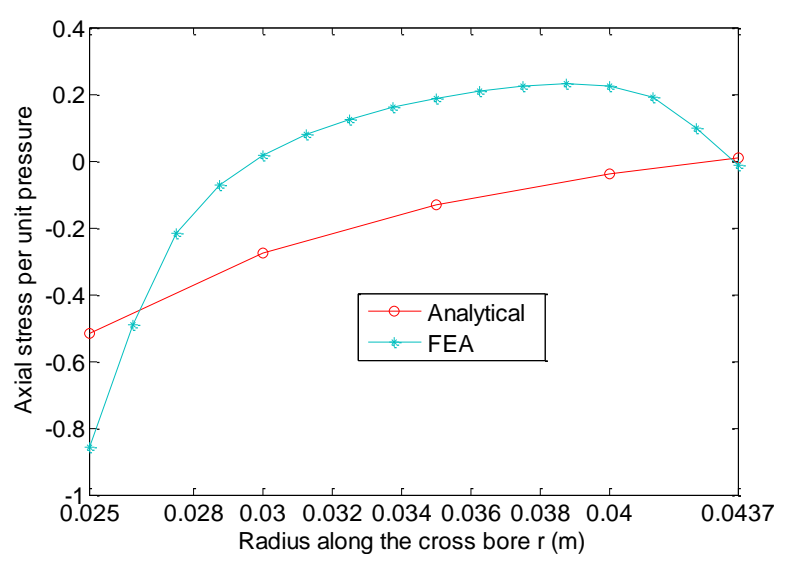

Figure $4: \mathrm{K}=1.75 \mathrm{CB}=0.1$
Due to the symmetrical configuration of the cross bore as shown in Figure 1, only an eighth of the structure was analysed. The cylinder was then loaded with internal pressure at both the main bore and the cross bore. Symmetrical boundary conditions were applied at the three cut sections of cylinder in $\mathrm{X}, \mathrm{Y}$ and $\mathrm{Z}$ global axes to enforce the correct symmetric behaviour as well as restrict rigid body motions. While, the displacement in $\mathrm{X}$ axis at the far end of the cylinder was constrained in order to induce the effects of the end enclosures. A detailed modelling procedure followed in this research work is presented in an earlier study by Nziu and Masu (2018).

\section{RESULTS AND DISCUSSION}

Axial stress component in the direction of the main cylinder

The axial stress per unit pressure along the transverse edge of the cross bore are presented under the following subheadings:

\section{Cross bore to main bore ratio of 0.1}

In this section, results of axial stresses in a thick-walled cylinder with a main bore to cross bore size ratio of 0.1 are presented in Figures 2-8 for $\mathrm{K}=1.4,1.5,1.75,2.0,2.25,2.5$ and 3.0.

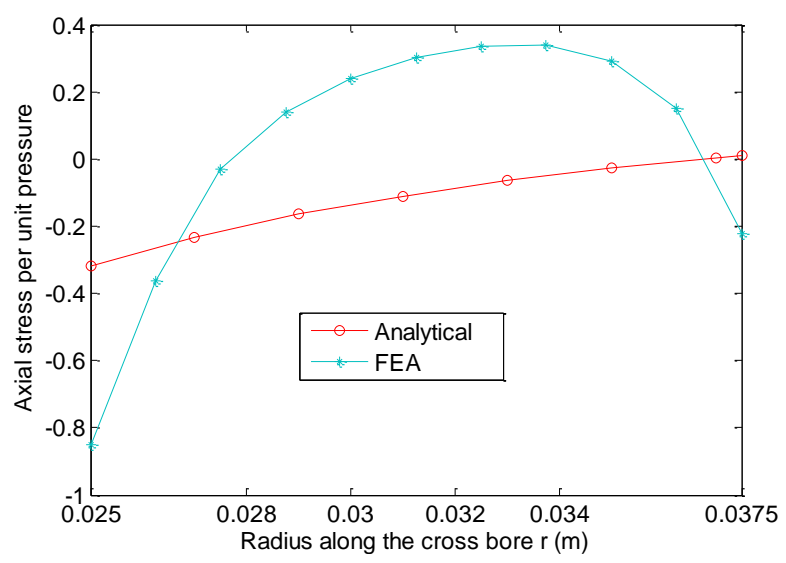

Figure $3: \mathrm{K}=1.5 \mathrm{CB}=0.1$

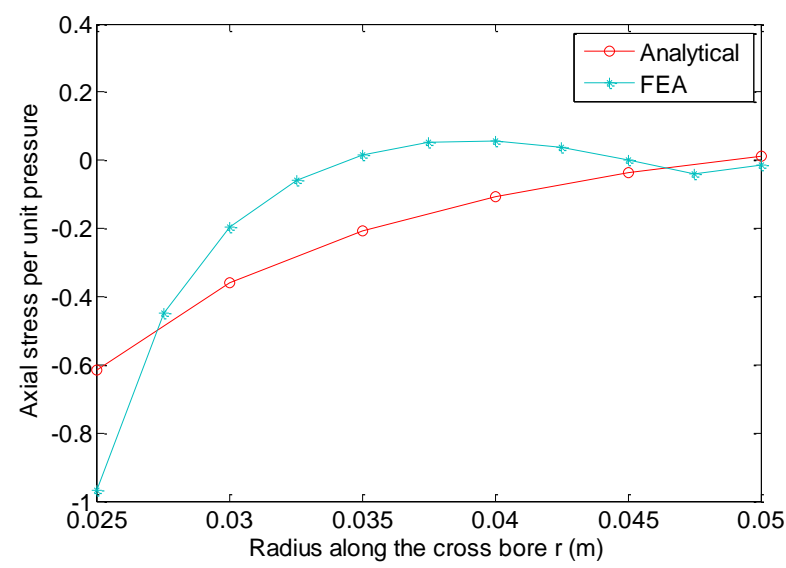

Figure 1: $\mathrm{K}=2.0 \mathrm{CB}=0.1$ 


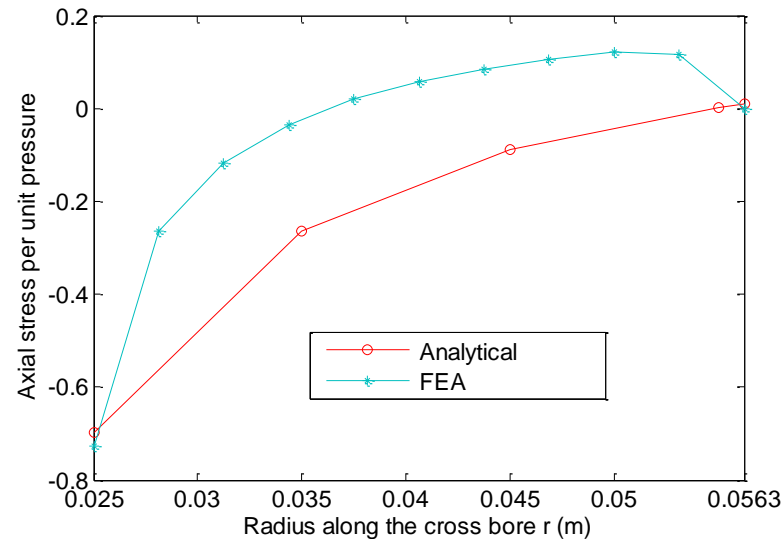

Figure 6: $\mathrm{K}=2.25 \mathrm{CB}=0.1$

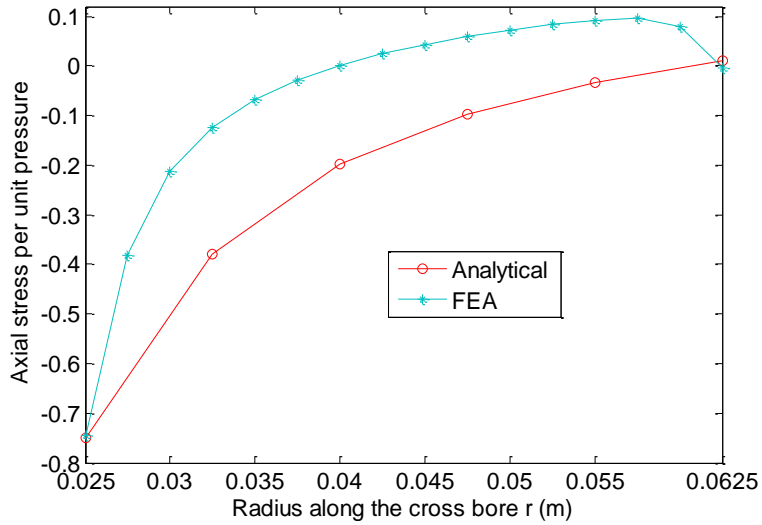

Figure $2: \mathrm{K}=2.5 \mathrm{CB}=0.1$

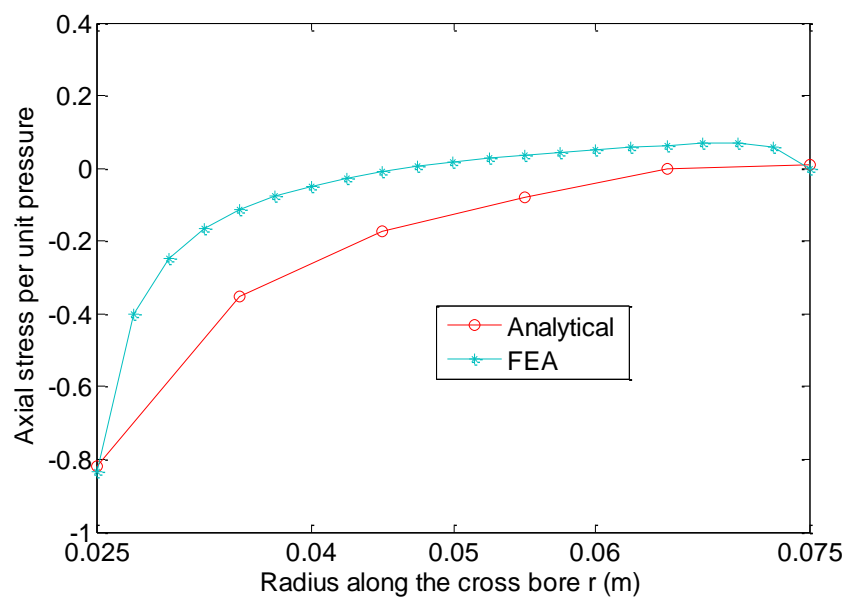

Figure 8: $\mathrm{K}=3.0 \mathrm{CB}=0.1$

Figures 2-8: Axial stress distribution per unit pressure for various thickness ratios along a radial circular cross bore, with a cross bore to main bore size ratio of 0.1 .

Generally, the disparity of stress distribution between the two methods was more pronounced in $\mathrm{K}=1.4$ as shown in Figure 2 , which reduced with an increase in thickness ratio. The axial stresses given by the two approaches along the cross bore were observed to change from a compressive state, at the intersection, to a tensile state along the cylinder thickness as illustrated in Figures 2 to 8. The lowest compressive axial stress per unit pressure at the intersection was given by the FEA approach. This occurred at $K=2.0$ with a magnitude of -0.968 , while the lowest stress from the analytical approach was at 0.079 for $\mathrm{K}=1.4$. Only in $\mathrm{K}=2.25,2.5$ and 3.0 were the stress predictions at the intersection by the two methods in good agreement as shown in Figures 6, 7 and 8.

On the other hand, the highest tensile axial stress was given by the analytical method at $\mathrm{K}=1.4$ on the outside surface of the cylinder with a magnitude of 0.901 . The FEA data produced a concave curve with a maximum turning point as shown in Figures 2 to 8 . The position of this turning point was noted to be skewed towards the outside surface of the cylinder. The maximum turning point occurred on $\mathrm{K}=1.4$ at 0.395 , whereas the minimum was on $\mathrm{K}=3.0$ at 0.0679 as illustrated by Figures 2 and 8, respectively. Except for $\mathrm{K}=1.4$ and 1.5, the axial stresses predicted by the FEA data at the outside surface of the cylinder was zero. Contrary to the plain cylinder, where axial stress is constant across the cylinder thickness, it was found to vary along the surface of the cross bore in all the studied cases.

\section{Cross bore to main bore ratio of 0.3}

Results of axial stresses in pressure vessels with a main bore to cross bore size ratio of 0.3 are presented in Figures 9 to 15 for $\mathrm{K}=1.4,1.5,1.75,2.0,2.25,2.5$ and 3.0. 
International Journal of Engineering Research and Technology. ISSN 0974-3154, Volume 13, Number 9 (2020), pp. 2332-2342

(C) International Research Publication House. https://dx.doi.org/10.37624/IJERT/13.9.2020.2332-2342

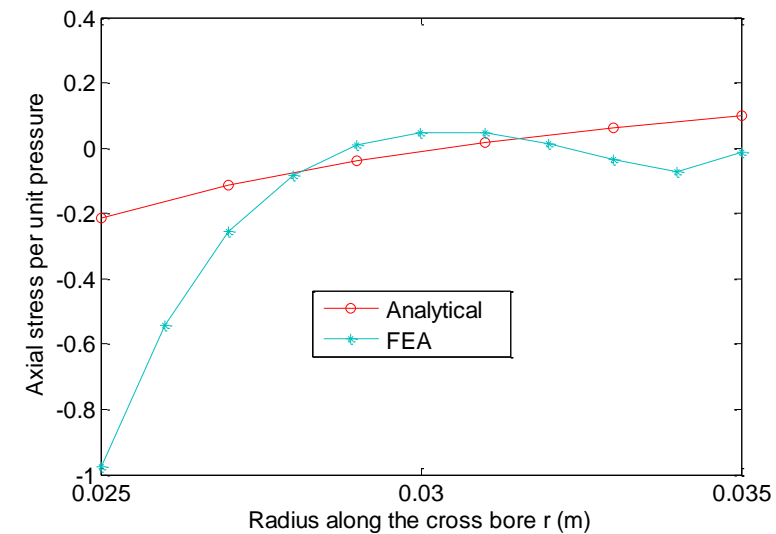

Figure 9: $\mathrm{K}=1.4 \mathrm{CB}=0.3$

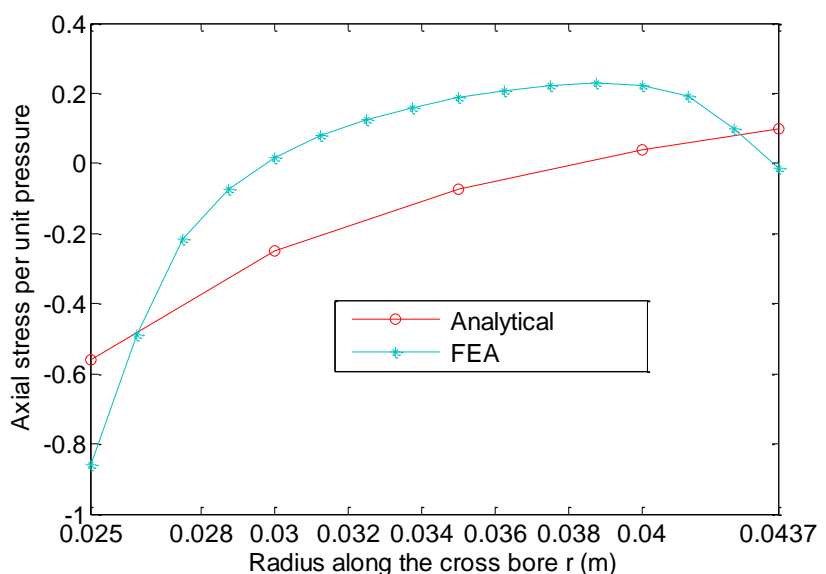

Figure 11: $\mathrm{K}=1.75 \mathrm{CB}=0.3$

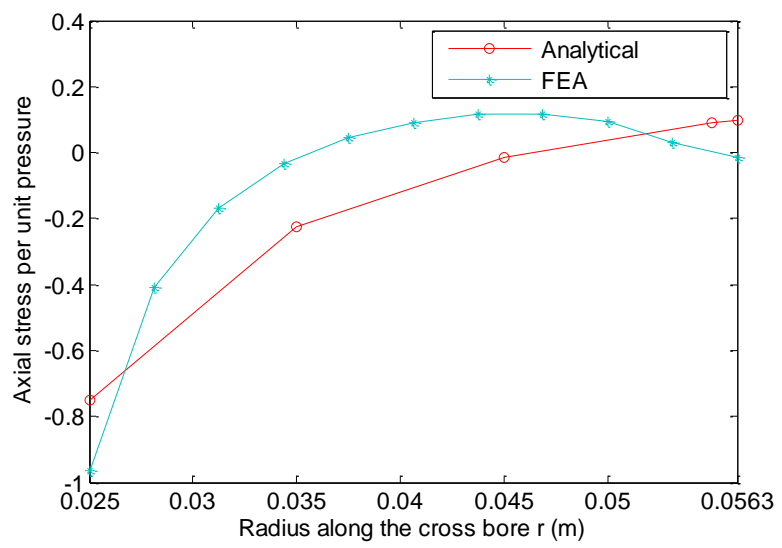

Figure 13: $\mathrm{K}=2.25 \mathrm{CB}=0.3$

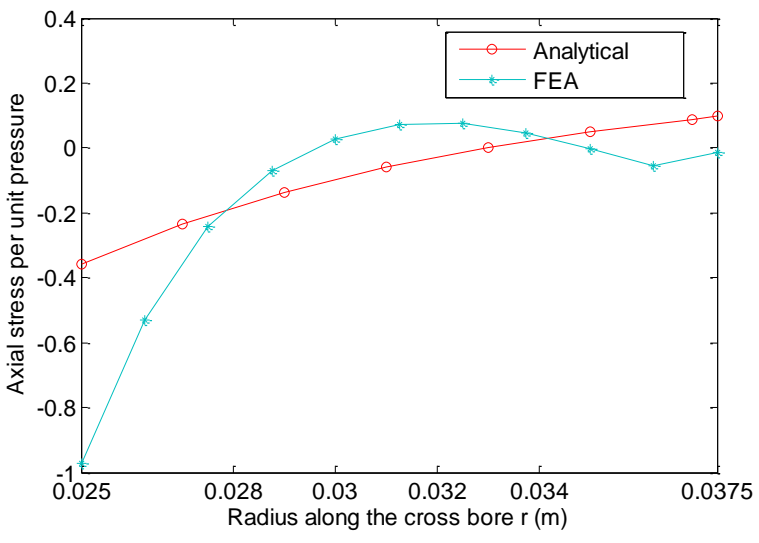

Figure $10: \mathrm{K}=1.5 \mathrm{CB}=0.3$

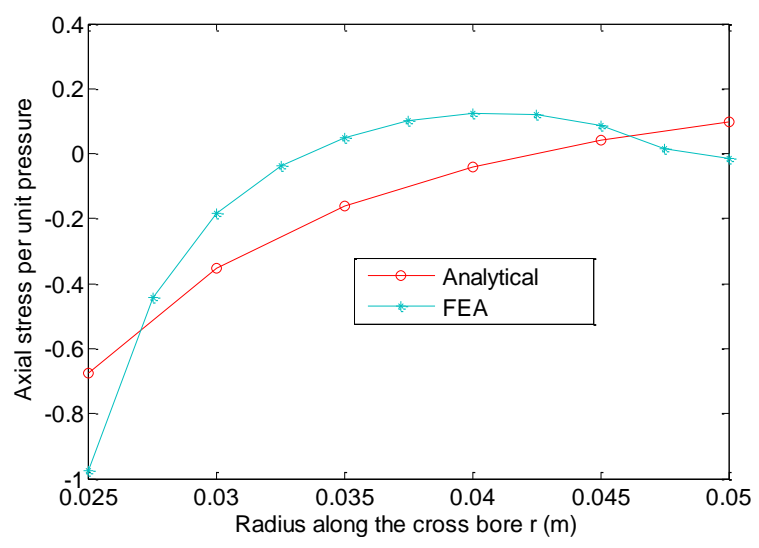

Figure 12: $\mathrm{K}=2.0 \mathrm{CB}=0.3$

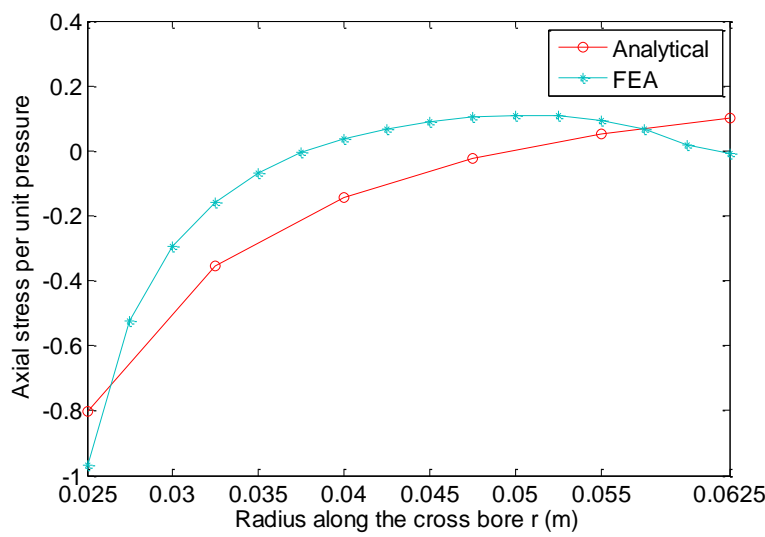

Figure 14: $\mathrm{K}=2.5 \mathrm{CB}=0.3$ 


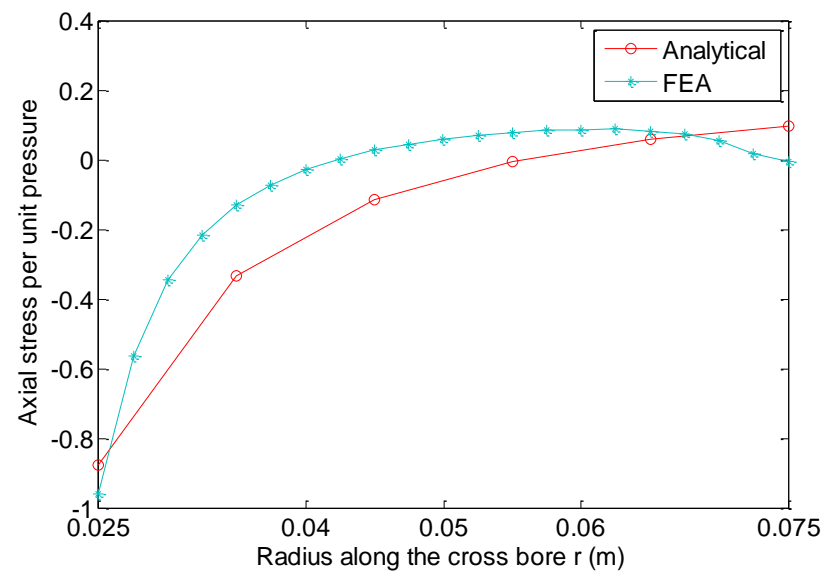

Figure 15: $\mathrm{K}=3.0 \mathrm{CB}=0.3$

Figures 9 - 15: Axial stress distribution per unit pressure for various thickness ratios along a radial circular cross bore, with a cross bore to main bore size ratio of 0.3 .

The axial stress distribution pattern observed in this section was similar to the one discussed in preceding section of bore ratio of 0.1 . The disparity in stress distribution given by the two methods at the intersection was higher in $\mathrm{K}=1.4$ and 1.5 as shown in Figures 9 and 10. However, this disparity in stress distribution reduced as the thickness ratio increased as seen in Figures 14 and 15. The compressive axial stresses at the intersection given by the FEA method ranged from -0.85 to 0.976 , with the maximum stress occurring on $\mathrm{K}=1.4$. These stresses determined by FEA were close to those predicted by a similar study by Ford and Alexander (1977). The study by Ford and Alexander had predicted a constant axial stress along the cross bore of magnitude of -1 .

The stress distribution given by the two methods, in the current study, along the surface of the cross bore was in close

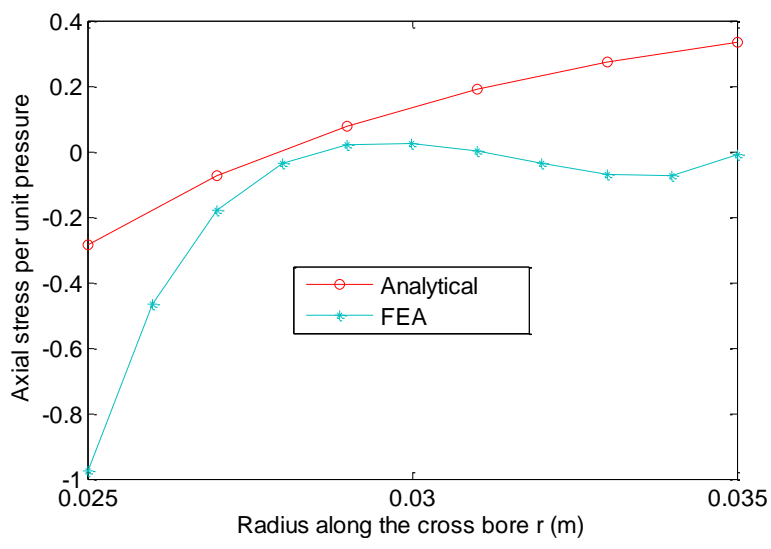

Figure 16: $\mathrm{K}=1.4 \mathrm{CB}=0.5$ agreement in $\mathrm{K}=2.0,2.5$ and 3.0 as illustrated by Figures 13, 14 and 15. The maximum tensile stresses given by the FEA occurred on $\mathrm{K}=1.75$ at 0.231 . Except for $\mathrm{K}=1.5$, the axial stresses at the outer surface of the cylinder wrer zero. The analytical approach gave the highest compression stress at the intersection as -0.878 at $\mathrm{K}=3.0$, whereas, the highest tensile stress occurred at the outside surface of the cylinder reaching a value of 0.1 in all the thickness ratios.

\section{Cross bore to main bore ratio of 0.5}

Results of axial stresses in a thick-walled cylinder with a main bore to cross bore size ratio of 0.5 are presented in figures 16 22 for $\mathrm{K}=1.4,1.5,1.75,2.0,2.25,2.5$ and 3.0.

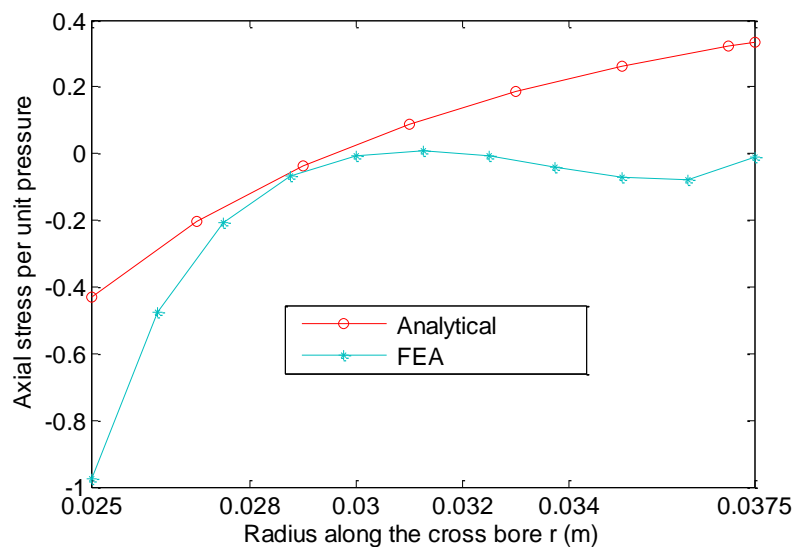

Figure 17: $\mathrm{K}=1.5 \mathrm{CB}=0.5$ 
International Journal of Engineering Research and Technology. ISSN 0974-3154, Volume 13, Number 9 (2020), pp. 2332-2342

(C) International Research Publication House. https://dx.doi.org/10.37624/IJERT/13.9.2020.2332-2342

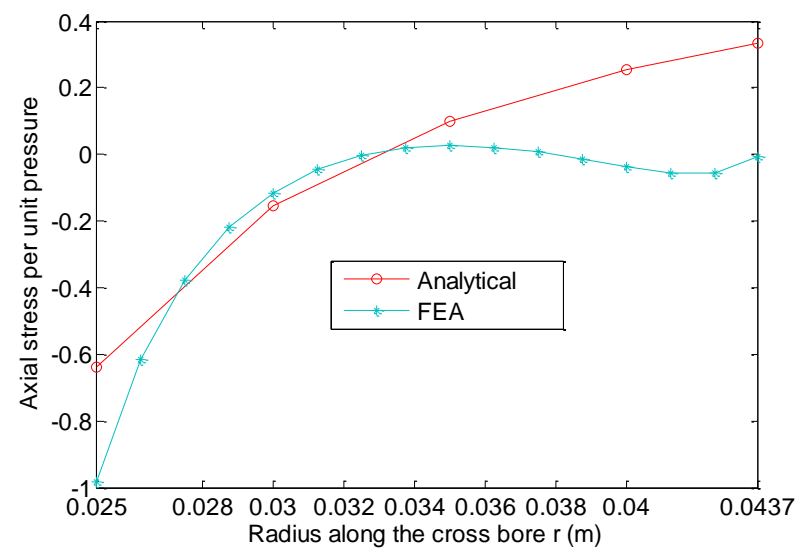

Figure 18: $\mathrm{K}=1.75 \mathrm{CB}=0.5$

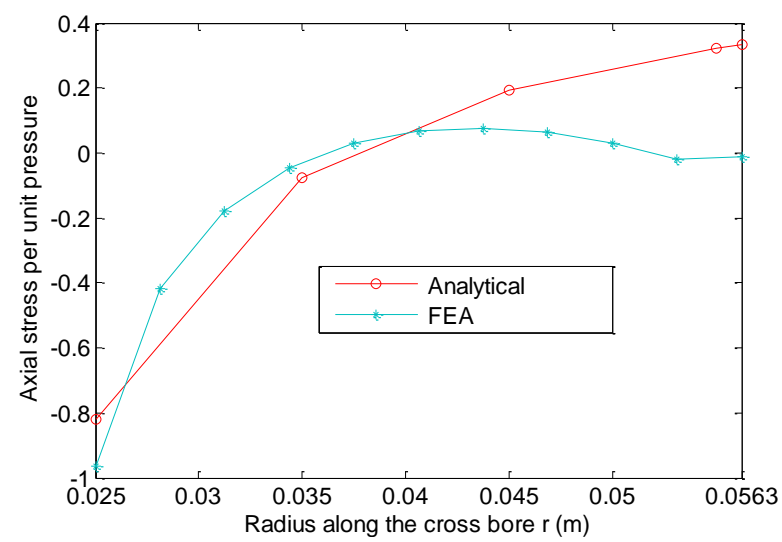

Figure 20: $\mathrm{K}=2.25 \mathrm{CB}=0.5$

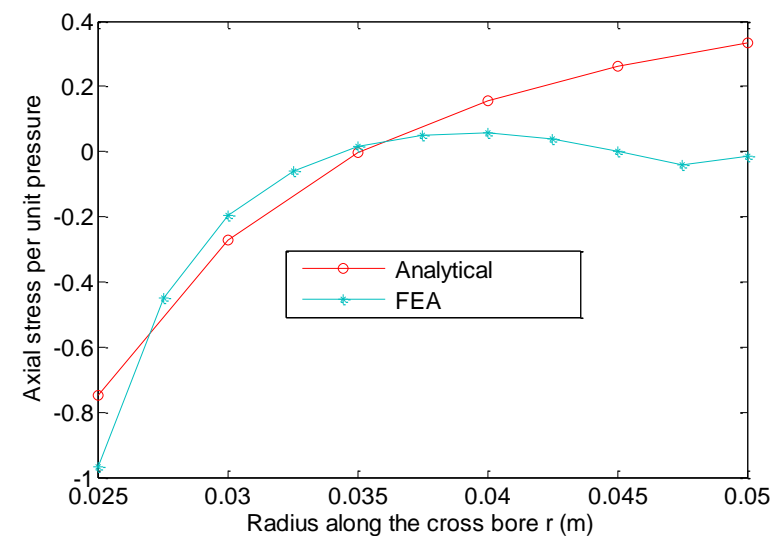

Figure 19: $\mathrm{K}=2.0 \mathrm{CB}=0.5$

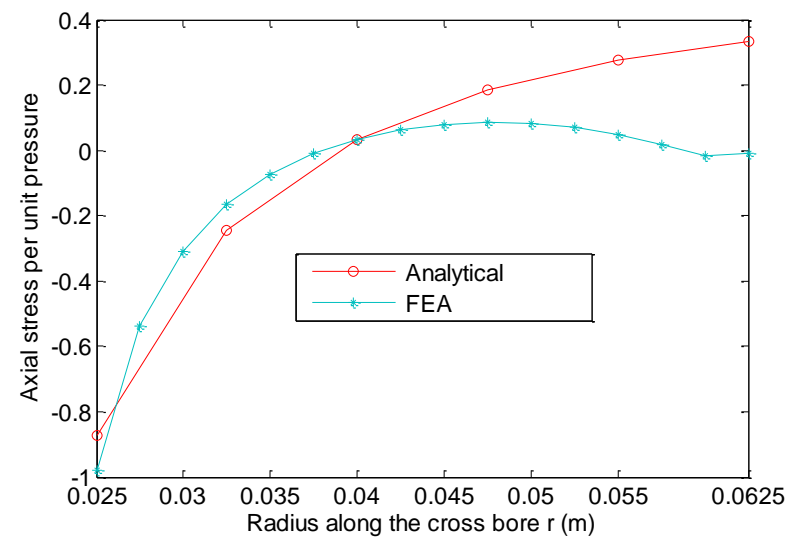

Figure 21: $\mathrm{K}=2.5 \mathrm{CB}=0.5$

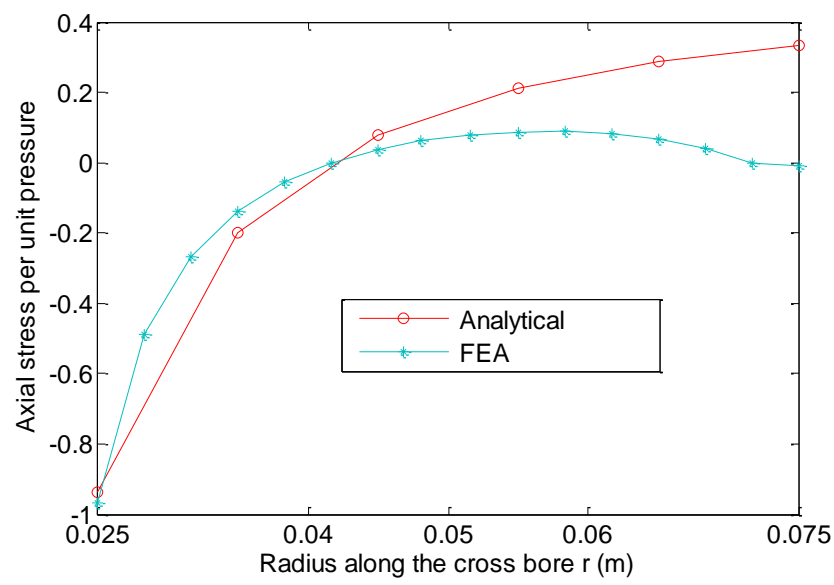

Figure 22: $\mathrm{K}=3.0 \mathrm{CB}=0.5$

Figures 16-22: Axial stress distribution per unit pressure for various thickness ratios along a radial circular cross bore, with a cross bore to main bore size ratio of 0.5 .

As illustrated in Figures 16 to 22, the stress distribution had similar patterns as observed in the preceding sections of bore ratios of 0.1 and 0.3 . The FEA method gave the highest compressive axial stresses at the intersection. The stresses ranged between -0.963 to -0.984 , being close to -1 . Moreover, for $\mathrm{K}=2.25,2.5$ and 3.0 the results from the analytical and
FEA at the intersection were in close agreement.

Furthermore, a good agreement in the prediction of stress distribution results by the two methods was seen in thickness ratios of $\mathrm{K}=1.75,2.0,2.25,2.5$ and 3.0. As shown in Figures 16 to 22 . The closest agreement in results between the two methods occurred only at the cross bore intersection, after 
International Journal of Engineering Research and Technology. ISSN 0974-3154, Volume 13, Number 9 (2020), pp. 2332-2342

(C) International Research Publication House. https://dx.doi.org/10.37624/IJERT/13.9.2020.2332-2342

which, there were large inconsistencies in the stress distributions between these two methods. These inconsistencies may be as a result of some of the assumptions made during the derivation of the analytical solution. For instance, large cross bores may introduce varying magnitudes of bending and shearing stresses along curved surface of the cylinder which is contrary to the assumptions made in the development of the analytical solution.

Except for $\mathrm{K}=1.5$, the data given by the FEA approach gave small values of tensile axial stresses. The highest stress value was reported at 0.0886 on $\mathrm{K}=3$. From the FEA results, it was
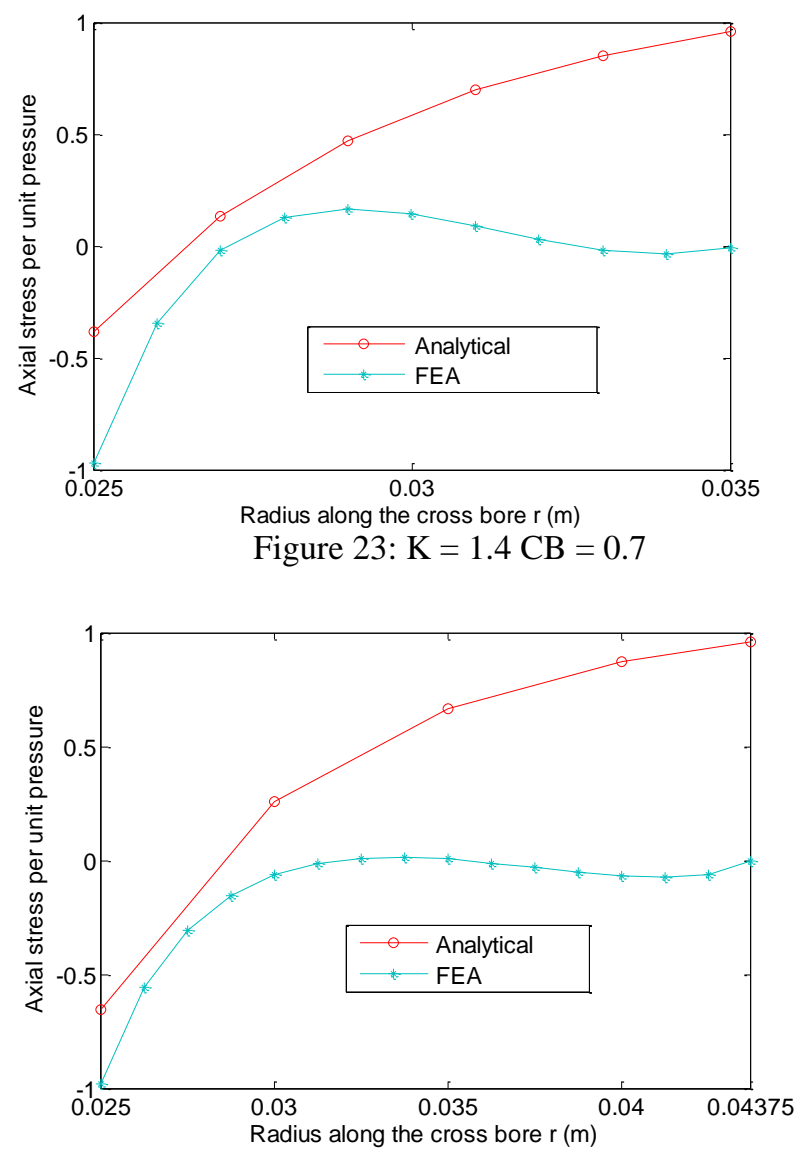

Figure 25: $\mathrm{K}=1.75 \mathrm{CB}=0.7$

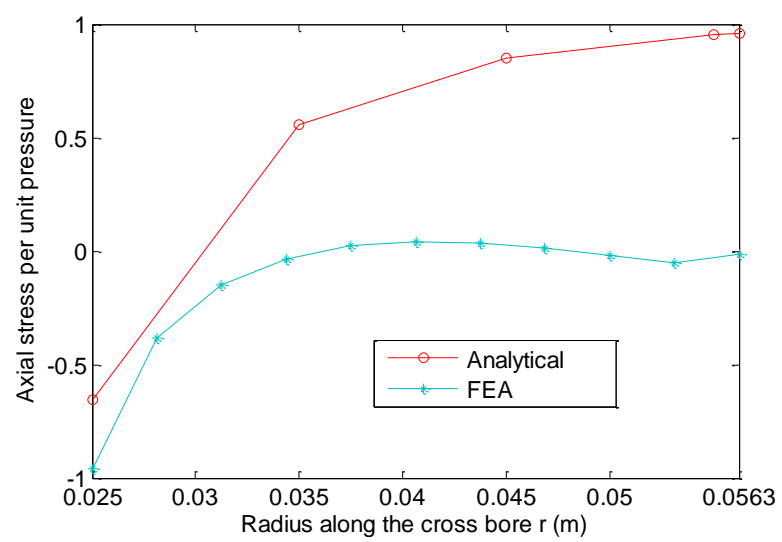

Figure 27: $\mathrm{K}=2.25 \mathrm{CB}=0.7$ noted that there were no axial stresses at the outside surfaces of the cylinders in all the thickness ratios. In contrast, the analytical method predicted high tensile stresses at the crossbore surfaces. The highest analytical stress had a magnitude of 0.0375 occurring at $K=1.5$.

\section{Cross bore to main bore ratio of 0.7}

Results of axial stresses in a thick-walled cylinder for cross bore size ratio of 0.7 are presented in Figures $23-29$ for $\mathrm{K}=$ $1.4,1.5,1.75,2.0,2.25,2.5$ and 3.0.

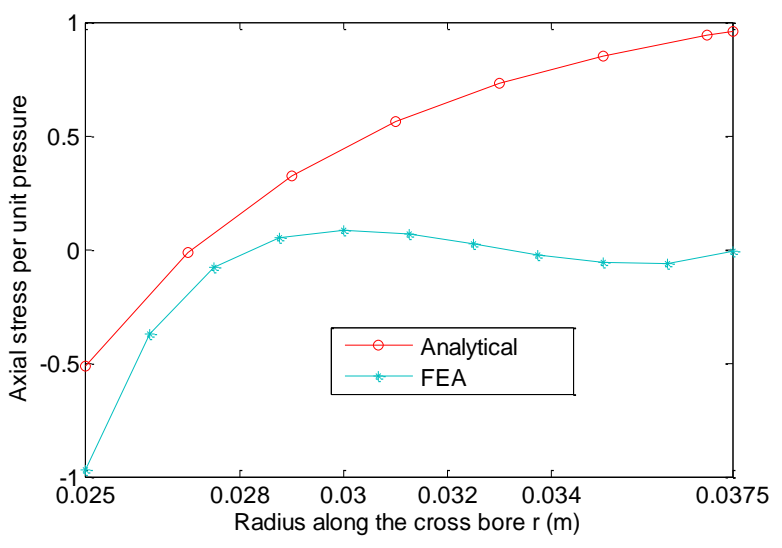

Figure $24: \mathrm{K}=1.5 \mathrm{CB}=0.7$

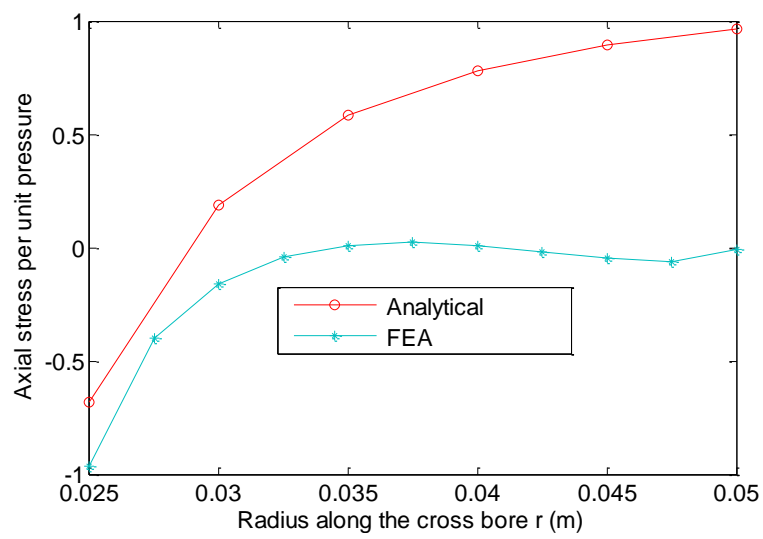

Figure $26: \mathrm{K}=2.0 \mathrm{CB}=0.7$

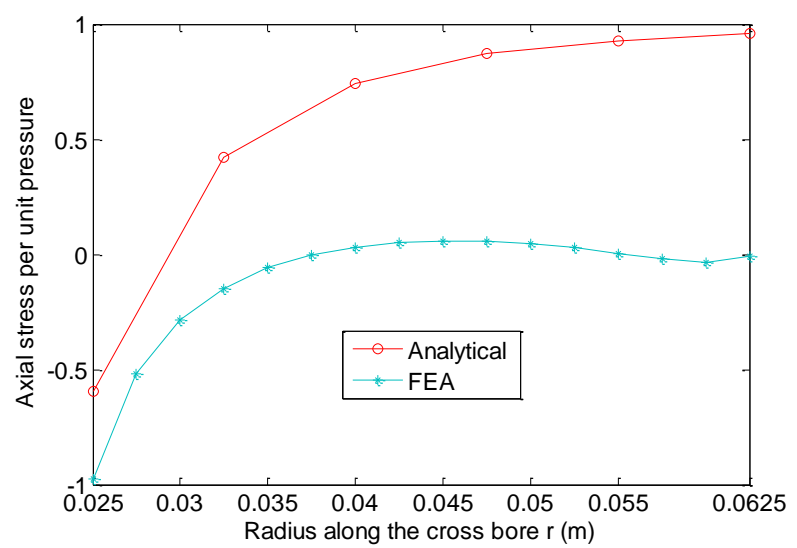

Figure $28: K=2.5 \mathrm{CB}=0.7$ 


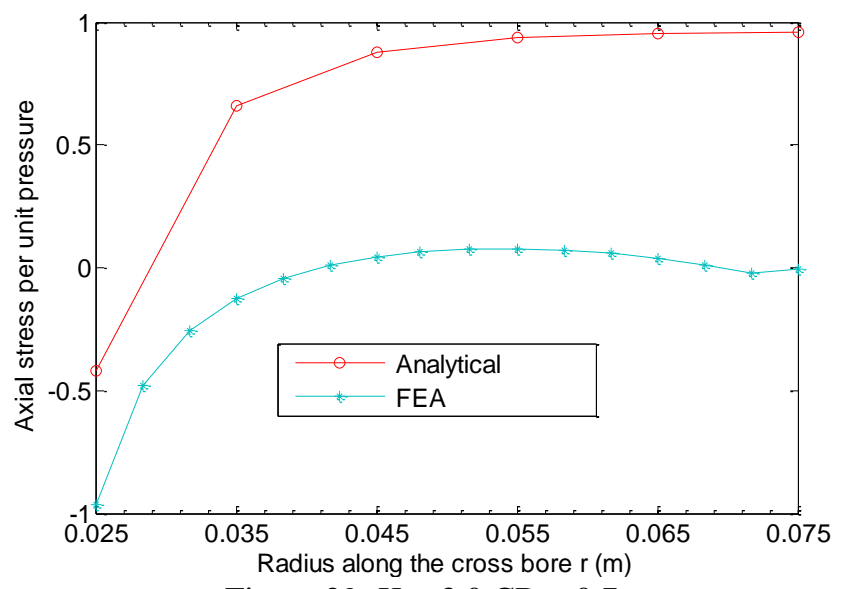

Figure 29: $\mathrm{K}=3.0 \mathrm{CB}=0.7$

Figures 23 - 29: Axial stress distribution per unit pressure for various thickness ratios along a radial circular cross bore, with a cross bore to main bore size ratio of 0.7 .

Inconsistencies in stress distributions predicted by the two methods on this cross-bore size were more pronounced in this cross-bore ratio than in the previous three ratios. These stress distribution inconsistencies are shown in Figures 25 to 29. The disparity between the two methods was seen to increase away from the intersection of the cross bore. From these illustrations, it was evident that there was no meaningful correlation between the results given by the two methods.

The FEA approach predicted compressive axial stresses at the intersection which ranged from -0.957 to -0.983 . In contrast, the analytical method gave lower stresses ranging from -0.382 at $\mathrm{K}=1.4$ to -0.68 at $\mathrm{K}=2.0$.

At the outside surface of the cylinders, the analytical method gave higher values of tensile axial stress than FEA approach in

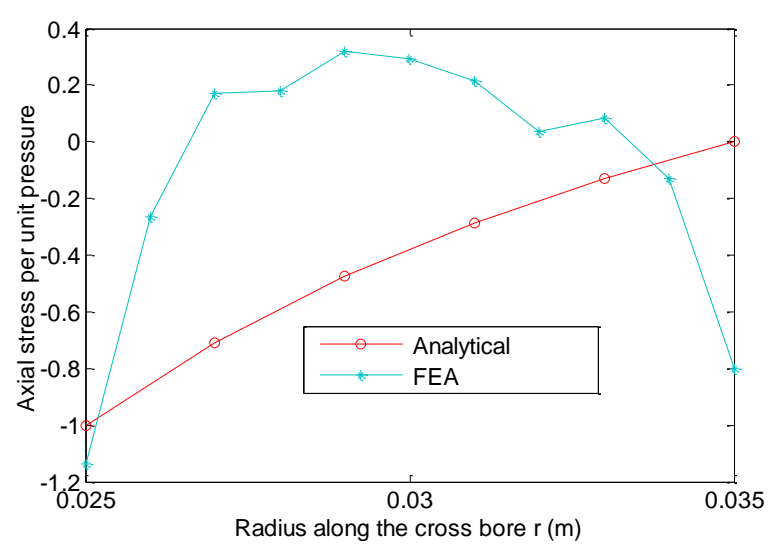

Figure 30: $\mathrm{K}=1.4 \mathrm{CB}=1.0$ all the thickness ratios. The stresses given by the analytical method were constant at 0.96 for all the thickness ratios. Conversely, the FEA method predicted zero axial stress at the same point. The highest tensile stress given by the FEA method occurred in $\mathrm{K}=1.4$ at 0.168 , whereas, the lowest was at $\mathrm{K}=$ 1.75 at 0.0143 .

\section{Cross bore to main bore ratio of 1.0}

Results of axial stresses in a thick-walled cylinder with cross bore size ratio of 1.0 are presented in figures 30 to 36 for $\mathrm{K}=$ $1.4,1.5,1.75,2.0,2.25,2.5$ and 3.0.

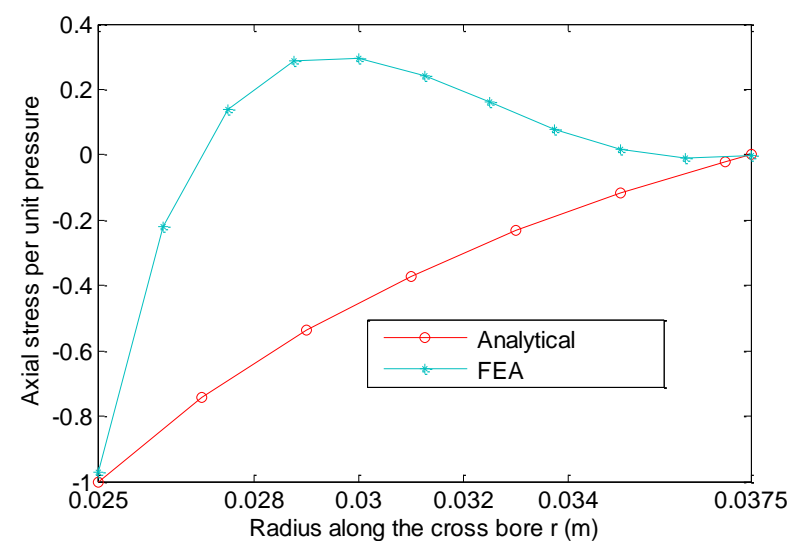

Figure $31: \mathrm{K}=1.5 \mathrm{CB}=1.0$ 
International Journal of Engineering Research and Technology. ISSN 0974-3154, Volume 13, Number 9 (2020), pp. 2332-2342

(C) International Research Publication House. https://dx.doi.org/10.37624/IJERT/13.9.2020.2332-2342

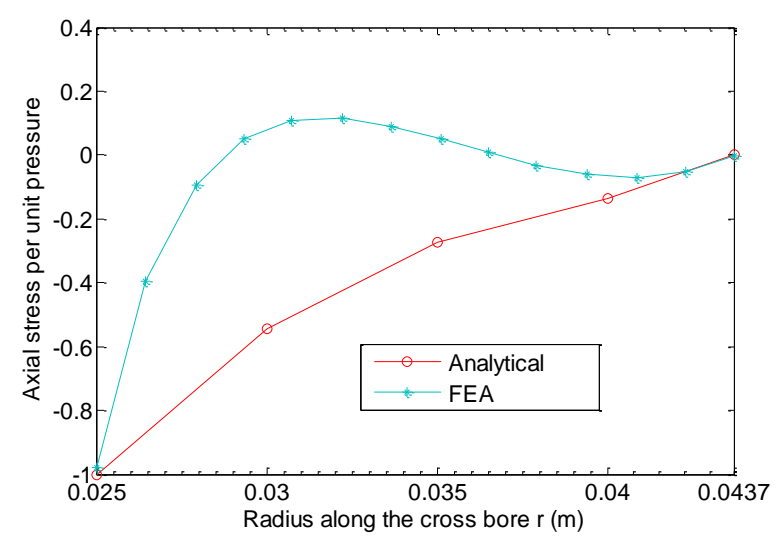

Figure $32: \mathrm{K}=1.75 \mathrm{CB}=1.0$

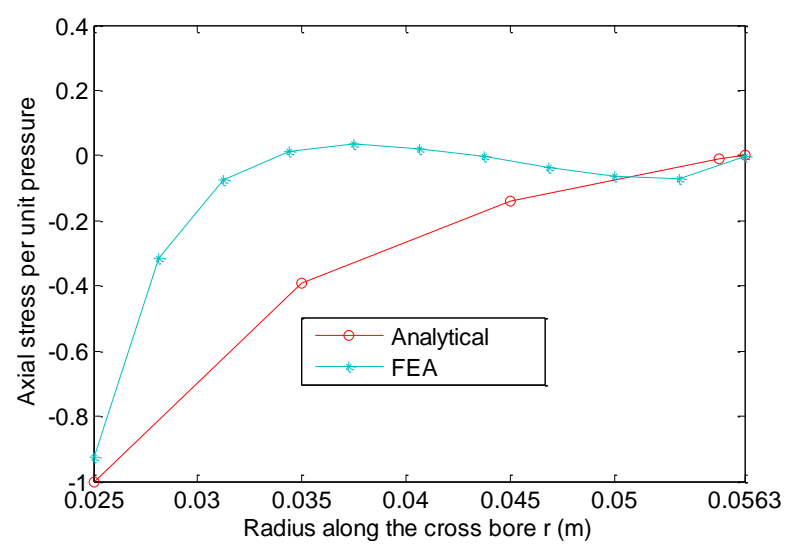

Figure $34: \mathrm{K}=2.25 \mathrm{CB}=1.0$

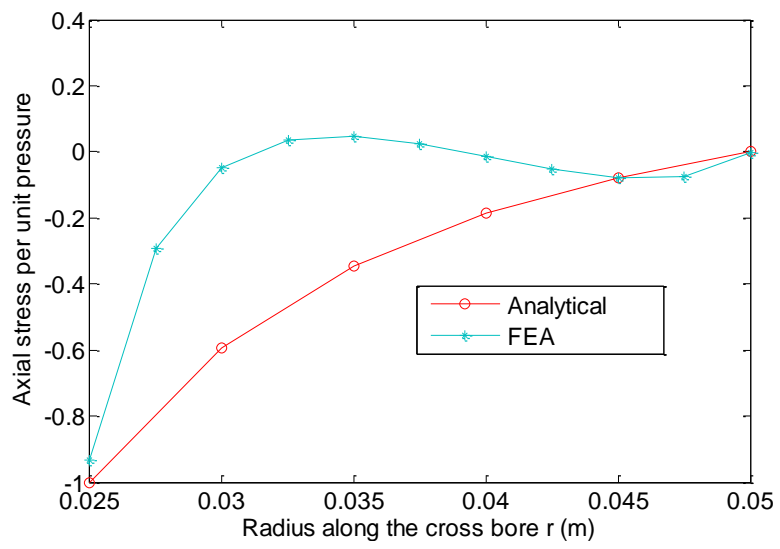

Figure 33: $\mathrm{K}=2.0 \mathrm{CB}=1.0$

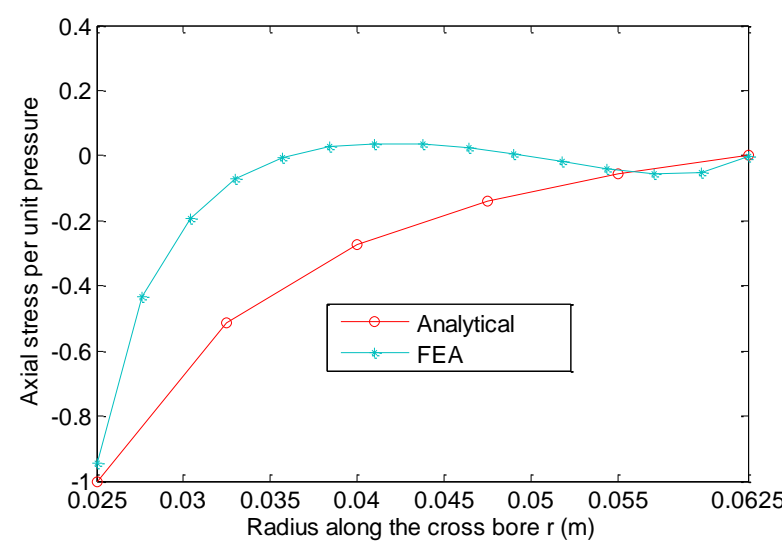

Figure $35: \mathrm{K}=2.25 \mathrm{CB}=1.0$

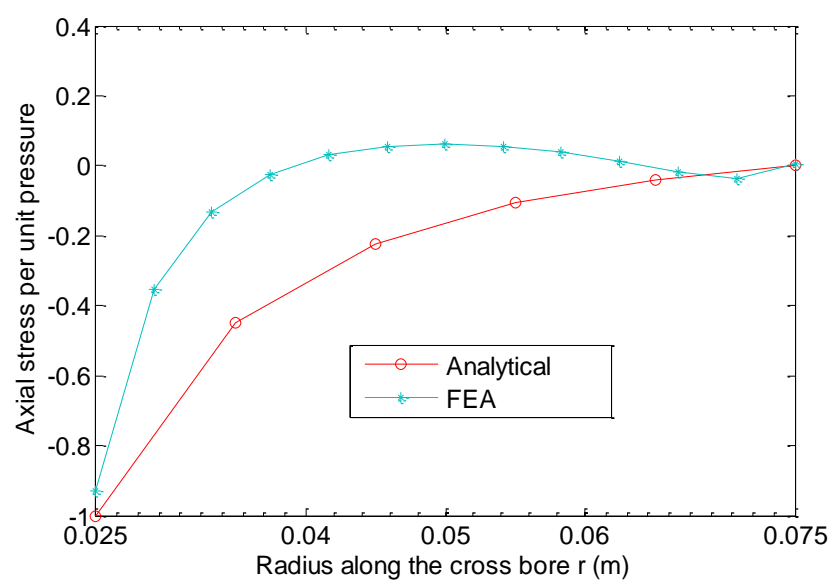

Figure $36: \mathrm{K}=3.0 \mathrm{CB}=1.0$

Figures 30 - 36: Axial stress distribution per unit pressure for various thickness ratios along a radial circular cross bore with a cross bore to main bore size ratio of 1.0.

Disparity in axial stress distribution between the two methods was more pronounced after the cross bore intersection as shown in Figures 30 to 36 . However, the disparity in stress distribution was minimal at the cross-bore intersection and at the outside surface of the cylinder.
The stresses predicted by the two methods at the cross-bore intersection were found to be in good agreement. The analytical stress at the intersection was compressive and constant at -1 for all the thickness ratios, whereas, the FEA stresses ranged between -1.137 at $\mathrm{K}=1.4$ to -0.924 at $\mathrm{K}=2.25$. With the 
exception of $\mathrm{K}=1.4$ for the FEA method, the axial stresses predicted by the two approaches at the outside surfaces of the cylinders were zero. The FEA approach at $\mathrm{K}=1.4$ predicted an axial stress per unit pressure of magnitude -0.803 at the same point. Therefore, no tensile axial stresses occurred in this crossbore ratio as predicted by the analytical method.

FEA method predicted a gradual change in stress distribution along the cylinder thickness, except for $\mathrm{K}=1.4$ where the stress varied sharply as shown in Figure 30. The tensile axial stresses resulting from the FEA method ranged from 0.0346 at $\mathrm{K}=2.25$ to 0.318 at $\mathrm{K}=1.4$.

\section{General discussion on the correlation of analytical and FEA solutions}

In general, the axial stresses were found to vary along the crossbore depth in all the studied cases. This observation contradicted the earlier studies by Faupel and Harris (1957) and Ford and Alexander (1977) which had indicated that the axial stress is constant along the cross bore. Usually, the total axial stress along the cross bore is the summation of the axial stresses generated by the main cylinder with a bore and the corresponding radial stresses produced by the pressurised cross bore when acting alone. Thus, the sum of these stresses varies along the transverse edge of the cross-bore. In addition, the presence of varying magnitudes of bending moments and shearing stresses along the transverse edge of the cross bore. This occurrence results to non-uniform stress field around the cross bore.

From the results presented in the preceding sections, it was evident that the developed analytical solution predicted correctly some of the axial stresses along the cross bore. In this study, the focus was mainly on the cross-bore intersection, where stresses were high. A summary of the cylinder sizes and their corresponding cross bore size ratios, where the analytical axial stresses' magnitudes were in agreement with FEA at the cross-bore intersection, is shown in Table 1.

Table 1: Axial stress at cross bore intersection where the analytical and FEA results were in good agreement.

\begin{tabular}{|l|l|}
\hline Cylinder thickness ratio $(\mathrm{K})$ & Cross bore size ratio \\
\hline $2.25,2.5$ and 3.0 & 0.1 \\
\hline 2.5 and 3.0 & 0.3 \\
\hline $2.25,2.5$ and 3.0 & 0.5 \\
\hline None & 0.7 \\
\hline All & 1.0 \\
\hline
\end{tabular}

Out of 35 models studied, the analytical solution predicted correctly the magnitude of the axial stresses in 15 models.

In brief, for small cross bores, the total axial stress is the summation of the axial stresses generated by the main cylinder with a bore and the corresponding radial stresses produced by the pressurised cross bore when acting alone.

Contrary to the assumption made in the derivation of the analytical solution, it was revealed that despite the magnitude of the axial stress being small it was not necessarily zero. Hence, the disparities in the analytical and numerical results. Moreover, the disparities in results resulting from the two approaches were attributed to some of the assumptions made during the solution development and the limitations of the Abaqus software. For instance, in the development of the analytical solution it was assumed that the cylinder curvature has no effect on stress distribution. In addition, it was assumed that the axial stress was constant along the cross bore. This assumption of constant axial stress was contrary to the axial results presented by this study. Nevertheless, the ability of the Abaqus software in predicting the stresses correctly at the surface was not confirmed. Therefore, this study recommends the use of a numerical software suitable for surface stresses.

\section{CONCLUSION}

The developed solution was able to predict correctly axial stresses at the cross-bore intersection in 15 out of 35 models analysed.

\section{ACKNOWLEDGEMENTS}

This work was supported by the Department of Mechanical Engineering, Vaal University of Technology, South Africa.

\section{REFERENCES}

[1] Comlekci, T., Mackenzie, D., Hamilton, R. and Wood, J. (2007),"Elastic stress concentration at radial crossholes in pressurized thick cylinders, Journal of strain analysis, Vol. 42, doi. Org/10.1243/03093247JSA251

[2] Ford, H. and Alexander, J. (1977), “Advanced mechanics of materials", John wiley and sons inc., Canada, second edition.

[3] Hearn, E. J. (1999), "Mechanics of materials 2", Butterworth-Heinemann, Great Britain, ISBN 0-7506 3266-6, Third edition.

[4] Masu, L. M. (1989), "The effect of cross bore geometry on the strength of pressure vessels", PhD thesis, University of leeds.

[5] Nziu, P. K. (2018), "Optimal geometric configuration of a cross bore in high pressure vessels", Doctorate thesis, Vaal University of Technology

[6] Nziu, P.K. and Masu, L. M. (2019a) "Formulae for predicting stress concentration factors in flat plates and cylindrical pressure vessels with holes: A review", International journal of mechanical and production engineering research and development, ISSN 2249-6890, 2019, Vol. 9, issue 5, pp. 753-770, doi: 10.24247/ ijmperdoct 201967 
International Journal of Engineering Research and Technology. ISSN 0974-3154, Volume 13, Number 9 (2020), pp. 2332-2342

(C) International Research Publication House. https://dx.doi.org/10.37624/IJERT/13.9.2020.2332-2342

[7] Nziu, P.K. and Masu, L. M. (2019b) Formulae to predict hoop stresses along the transverse XY plane of a small radial circular cross bore in thick cylinders, International journal of mechanical \& production engineering research and development" ISSN 2249-6890/2249-8001, Vol.9, issue 6, pp 707-724, doi: 10.24247/ijmperddec201960 